\title{
Sixteen Semesters of Chemistry at the University of Zürich: A Retrospective on a Formative Time
}

\author{
Peter Wipf ${ }^{\star}$
}

Abstract: Anecdotes of a chemist's roadmap from Aargau to Zürich, Virginia, and Pennsylvania.

Keywords: Organic chemistry $\cdot \mathrm{OCl} \cdot$ University of Zurich

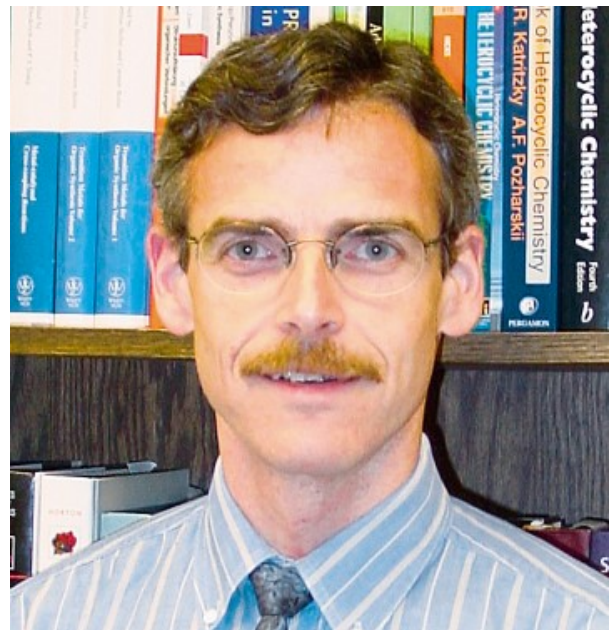

Peter Wipf
Rare are the opportunities that have lead me back to my alma mater on the Irchel campus since my departure in 1987; however, like for a good wine, my appreciation of those select vintage years, as well as for the 'vintners' who blended my Chemistry foundations, grows more profound with every turn of the globe.

My home and early schooling were based in Staufen, Lenzburg and Aarau, in the heart of the Canton of Aargau. Albeit unknown to me at the time, the Aargau was endowed with an august chemical heritage in Switzerland. In 1804, Daniel Frey established a chemical workshop in Aarau, predating by over a decade the first chemical production (Schnorf Brothers) at Uetikon near Lake Zürich, and by a half-century the synthetic dye production in Basel (Clavel, Durand, and Marnas) and what later became the 'Chemische Industrie in Basel' (CIBA). The Frey legacy in chemistry lived on for generations in Aarau, and led in 1887 to the foundation of the Frey chocolate brand. Two famous alumni of the OCI were raised in Aargau: Paul Karrer (Nobel Prize in Chemistry in 1937) attended school in Lenzburg and Aarau, and Albert Hofmann (discoverer of LSD) was born in Baden. Even Albert Einstein and another Swiss Nobel Prize winner, Werner Arber, lived for some time in Aarau. Among such bright beacons, I began looking for my own path to new discoveries, early on recognizing the value of technical resources and wellequipped with grammar school Electronics and Chemistry sets!

In 1979, after graduating from the Kantonsschule Aarau, I had decided to enter basic military training, and therefore I arrived a few weeks late in November for my first semester at the University of Zürich.
My tardiness may, in fact, have been an advantage, as I was thoroughly grateful to be able to spend my time in the wellheated, wood-paneled lecture rooms on the Irchel that so strongly juxtaposed my recent training among the frozen peaks of the Engadin. In addition, I had read up on all aspects of life as a student and had even gotten my hands on an updated edition of the all-encompassing brochure 'Das Studium der Chemie und Biochemie an der Universität Zürich'! I was particularly excited about the perspective on the goals for the study of Chemistry formulated in this brochure - “... to inspire and develop abilities that empower the individual to newly discover processes in nature or laboratory, logically analyze them, and independently develop toward a broadening of scientific knowledge... as well as apply this knowledge for the benefit of mankind and the environment, whereby the chemist contributes to the solution of general problems." What a great objective for the education of ambitious and idealistic students, and what a pity that as a collective, we chemists have failed to convey these noble goals of our profession to the majority of our fellow citizens! In 1984, the year of my graduation as a Diplom Chemiker, the Bhopal disaster shook the world, and in 1986, a fire in Schweizerhalle struck close to home and further highlighted the dangers of chemical manufacture. A backlash in the public opinion made it difficult to propagate the many beneficial contributions of chemistry to our standard of life. Unfortunately, and despite great strides in research, these challenges to the public image of chemistry have far from subsided and are nowadays omnipresent all over the world. 


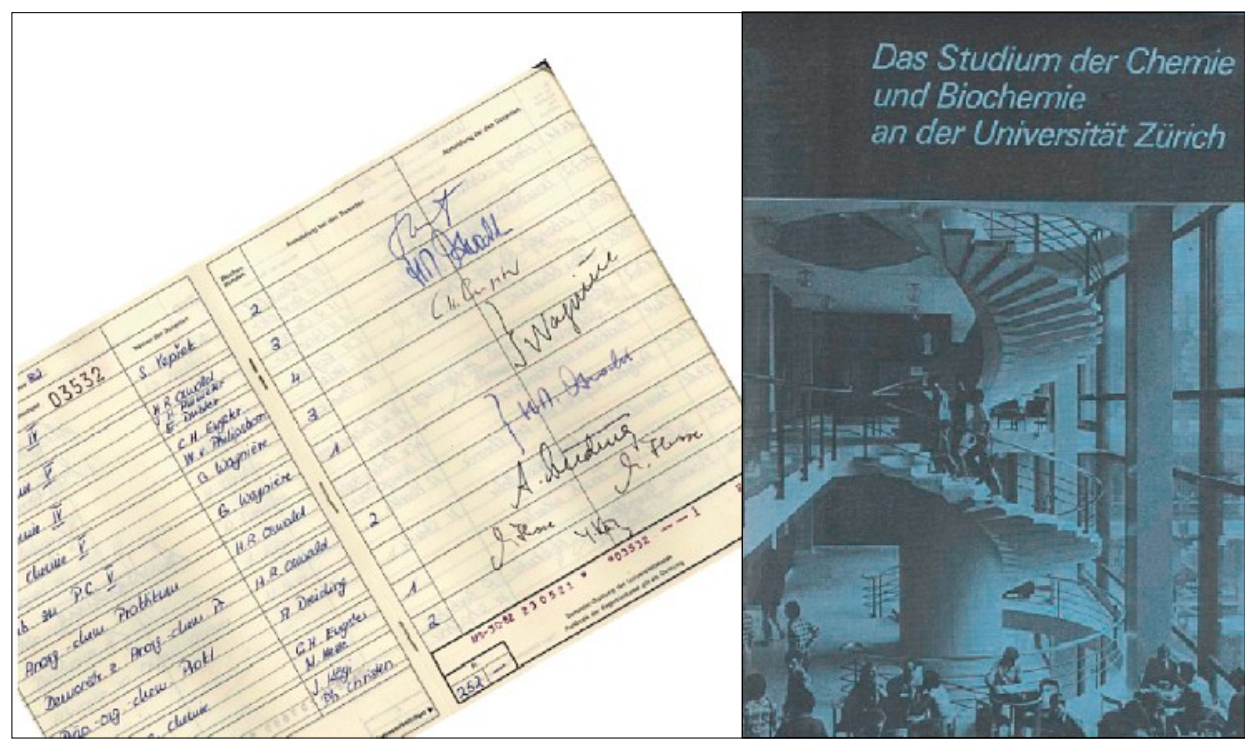

The diploma student's all-important 'Testat' and the brochure for students of chemistry and biochemistry

While the public relations of chemistry turned dire, my own hands-on experience with the subject grew more exciting and stimulating by the year. I found that organic chemistry provided me with the ideal mix of theory and practical applications, and after completing my pre-diploma courses, I joined the laboratory of Prof. Heinz Heimgartner. This selection was to a large extent based on the high professional standards of Prof. Heimgartner and by his fascinating research on the synthesis and properties of strained ring systems such as the azirines. Furthermore, I was attracted by the enthusiastic group of students in the E-labs, which included my friends Christjohannes Jenny, with whom I enjoyed many discussions on the meanings of science and life, and Walter Huggenberg.

My diploma work offered me an intimate experience with the rollercoaster that is research: while my initial attempts to generate a 3-oxazoline according to a literature protocol failed miserably, I was subsequently able to develop an alternative synthesis that, while limited in scope, provided the target ring system conveniently in a one-pot reaction! Exhilarated by the success and the ensuing two publications in Tetrahedron Letters and Chimia, I set my sights on a $\mathrm{PhD}$ project on the preparation of peptides containing $\alpha, \alpha$-disubstituted $\alpha$-amino acids with amino- $2 H$-azirines in the Heimgartner lab. Shortly before my promotion in the summer of 1987, I also applied for a Swiss National Science Foundation postdoctoral fellowship that would allow me to round off my education with an internship in the United States. For a brief instance, I had also considered venturing to Japan, but the advantage of improving my English language skills in the US trumped the opportunity to immerse myself in a more distant culture.
A collateral effect of attending a couple of years of Thursday night seminars in the realm of the Vasella group had been an increasing interest in synthetic strategy and natural product total synthesis. Therefore, I applied to several leaders in this field for a postdoctoral position, including Prof. Robert E. Ireland who had just moved from Caltech to UVA via a one-year stint at the Marion Merrell Dow research institute in Strasbourg. I felt particularly comfortable with selecting the Ireland laboratory, as one of my predecessors in the Heimgartner group, Daniel Obrecht, had provided us with feedback of the rewarding experience of his work with Prof. Ireland. Daniel had been highly stimulated by the challenges of total synthesis after his methodology studies during his $\mathrm{PhD}$. Apparently Bob Ireland had come to appreciate the experimental laboratory training provided in Switzerland and was a firm believer in the magical powers of 'Swiss hands'. It was a minor detriment that my arrival in the United States coincided with a major snowstorm across the East Coast. After two flight cancellations and a mid-night bus ride from JFK to Washington, I arrived in Charlottesville, Virginia - only to find that the whole city had shut down due to the twenty inches of snow on the ground. My luck soon turned, as Prof. Ireland provided me immediately with a warm welcome and the opportunity to work on two of the 'hottest' target molecules $d u$ jour - esperamicin and FK-506. The challenges were once again intense, but my experiences in the Ireland lab were also immensely rewarding and prepared me well for my next move.

With the completion of my postdoctoral studies in Charlottesville came the end of a quite traditional course of education, and I was strongly inclined to continue along this trajectory and return home to a position in the Swiss pharmaceutical industry. However, it was ultimately too tempting to finally 'do the unexpected' and stray away from the obvious career path. In the winter of 1990, I accepted a position as an Assistant Professor at the University of Pittsburgh.

Occasionally, I am asked to compare the US and Swiss systems of higher education. Different countries, to some extent, have different expectations for the professional qualifications of chemists, and people are, in part, a product of their environment and therefore require different training. Not surprisingly, the optimal system for producing synthetic organic chemists might be a hybrid of the middle-European and the US systems. Highlights of the European undergraduate education are a clear focus on chemistry, biology, physics and mathematics, with considerable exposure to specialized laboratory course work, comprehensive exams, and the requirement for a six- to nine-month research thesis. The US graduate system excels in its coverage of the current literature, a healthy level of elitism, and high expectations for independent contributions at the bench during $\mathrm{PhD}$ studies. In addition, a well-chosen postdoc position, much more common in the US than in many parts of Europe, is still a major advantage in broadening the horizon and expanding professional networking.

It is difficult to fully appreciate the benefits of an environment prior to venturing out of it. Over eight years, the Chemistry Institutes at the University of Zürich provided me with great colleagues, excellent resources, dedicated mentors, and a wellrounded education. I came to realize just how valuable this experience was when I interacted, and competed, with new colleagues from all corners of the world, and when I took the plunge into my own academic career far away from my center of origin. I remain deeply grateful to the Swiss system of basic and higher education, and, in particular, to all the teachers and peers who taught me that there is always a new question behind every answer.

\section{Acknowledgment}

Thanks to Prof. Jay Siegel and Ms. Sarah Macfarlane for helpful comments.

Received: February 11, 2008 